\title{
Locating the Sound of Trauma Within me. In and Out of Memory: Exploring the Tension Between Remembering and Forgetting a Traumatic Event.
}

\author{
Dr. Anna Walker \\ Plymouth University \\ Transtechnology Research Group \\ Drake Circus, Plymouth PL4 8AA, United Kingdom \\ anna.walker@plymouth.ac.uk
}

\begin{abstract}
The process of making sonic work for my PhD was very much about discovering the something that lay beyond the noise. Difficult to verbally articulate, or express through words, the something remained unknown until the violence of the noise was finally embodied. It was only through taking the noise into my body that the concept of silence could be fully comprehended. Simon Reynolds writes about noise as "a wordless state in which the very constitution of ourselves is in jeopardy," "an eruption within the material out of which language is shaped" (2006).
\end{abstract}

Noise: It's 2012, I am seated in an auditorium in Plymouth, listening to noise musician Merzbow played really loudly by Salome Voegelin. I have a flashback. The past becomes present and the current present disappears. I am back in New York. The Twin Towers falling, and I am hearing their collapse for the first time, despite having been there on the day.

This essay is an exploration of the differing qualities and layers of silence into which the loudness of the falling towers had become enmeshed and the necessity to unravel their noise in order to locate the concept of an inner silence.

Noise. Trauma. Hauntology. Freud. Jacques Derrida. Salome Voegelin. 9/11. Cathy Caruth.

\section{INTRODUCTION}

On September 11, 2001, the first plane flew over my building in downtown Manhattan while I was on the phone with my brother in London. He had just found out he was to be a father, mid-sentence the loud and heavy drone of a low flying 767 filled the room. 'What was that noise?' he asked. In the near distance, there were the sounds of an explosion, my building shook. NPR (National Public Radio) was on in the background, a man shrieked "Oh my God! Oh my God! A plane has just flown into the North Tower." The phone went dead, the radio followed. Everything changed. (Walker, 2016)

\section{BACKGROUND}

The starting point for my $\mathrm{PhD}$, In an $d \mathrm{O}$ ut of Memory: $E$ xploring $t$ he $T$ ension Between Remembering and Forgetting When Recalling 9/11, a Traumatic Event, was a personal remembering of 9/11 layered upon a well-established collective memory of the event. It involved deconstructing a journal written in the days before, during and after the attack, which had remained unread until beginning the research. Making work from this place functioned on a number of levels:

(i) An exploration of trauma from the inside out where memories and the body became a holding place for trauma.

(ii) The externalisation of trauma to further an understanding of the collective memory.

(iii) A personal bearing witness to a global trauma that was hijacked by the media.

(iv) An application of psychoanalytical writings on trauma to support an autoethnographic methodology.

Through a reclamation of the past, I was mourning and memorialising, contextualising, remembering, and contributing to a wider epistemological discussion on trauma. 
In 2012, two years into the research while attending a conference at Plymouth University, Salome Voegelin played loudly a sound-work by the noise musician Merzbow. I had a flashback. The past became present and the current-present disappeared. I was back in New York watching The Twin Towers fall, hearing their collapse for the first time, despite having been there on the day. Out of that experience came the sound and moving image artwork, Six Fragments (2015-2017). In it I am exploring the concept of having silenced the events on September 11th, 2001. The artwork is an examination of Derrida's notion of hauntology, of absenting something from memory and discovering what exists in its absence. It is also about the repercussions of a lingering anxiety, and a future full of danger.

The flashback upsets and interrupts the order of things. It ruptures bodily systems, creating moments of conflict and danger. Theorist, Cathy Caruth, describes the traumatised as being possessed by the image or the event in which the flashback functions as a foothold or trace back into the past, "a form of recall that survives at the cost of willed memory or of the very continuity of conscious thought" (1995). She writes how the traumatised contain an impossible history within them, where: "they themselves become a symptom of the history that they cannot entirely possess" (ibid). Flashbacks are therefore a means to bear witness to a past, they are clues, glimpses of a traumatic event and though they create untold problems through their disruption, flashbacks also function to alert us to the danger of a past that remains unresolved. For Bergson:

the past to which he returns is fugitive, ever on the point of escaping him, as though his backward turning memory were thwarted by the other, more natural memory, of which the forward movement bears him on to action and to life (2004).

Embedded within the flashback is the urge to restore, to regulate and integrate the past. Freud understood the flashback as traumatic repetition and linked it to the death instinct: "a compulsion to reproduce that very experience of chaos and trauma" (Laub, Lee, 2013). Conceptually, the flashback is a contradiction. The somatic desire to release the past trauma through remembering is simultaneously defended against by not remembering, thereby reproducing traumatic affect through the inevitable return of the past through flashbacks. Further complicated because the death instinct is: "by definition, considered to be silent, obscure, and resistant to clinical verification" (Laub, Lee, 2013). The moving image and sound-work, Falling, "ii made in 2016, begins to unravel the notion of the flashback.

\section{FALLING}

Falling, is the second fragment of the work 'Six Fragments'. Just 1.12 minutes it marked the beginning of an endeavour to understand noise and embody a silence that, unbeknownst to me, had not existed since September 11th, 2001. Created to be played loudly in a large theatre, with speakers that could accommodate low frequencies, I wanted Falling to be felt as well as heard. My aim was to break down the concept of silence into a felt quality of noise-a noise that is touchable. As the explosive sounds emerged, the hidden and the inaccessible memories also began to surface and alongside it the differing qualities and layers of silence into which the loudness of the falling towers had initially been buried. The work was the first step towards creating a language outside of words to express what was indescribable, what was unspeakable and what I had silenced for over a decade.

Registering the noise of the past was also to acknowledge an internal violent blocking of the sound, a rejection and spitting out of the event as it happened. In the discovery of such absence, it was necessary to re-discover not only the violence of the sound of the trauma, but the original violence that it took to void this aspect of the past. In other words, it was necessary to recognise the inner defence mechanisms in play to protect against the violence of the traumatic event and therefore the fierceness of its safeguarding, a violence unto the self that on some level must be undone and relived for the trauma to be integrated.

The visuals for Falling were edited from hours of footage filmed with a macro-lens directly from the computer screen to represent a visual rendering of the explosive noise of the towers falling, while the sonic component was an attempt to describe the uncontainable loudness of their disintegration. The noise symbolises and represents the wound. In Noise $M$ atters (2013), Greg Hainge usefully references Barthes concept of the visual punctum that allowed me to begin to unravel an aspect of noise. He writes, "For noise, much as we might try to contain it, reduce it, sublimate it, eradicate it, has the potential to affect us, to pierce us in this way". This begins to explain the refusal to remember, the rejection of the loud and violent noise of 9/11 for over a decade. Such a rupture with all of its loudness, creates a level of instability in the present that has the power to conjure up a terrifying vision of the future, thereby pushing the listener to a place where the he/she does not want to go. The punctum held within the artwork, Falling, calls upon the listener to remember, and in so doing continues to wound but justifies the wounding as necessary for it connects perception and cognition, traveling far beyond its representation. Noise here creates an intensity and depth from which there is no 
escape. It constitutes a force beyond just the parameters of film and sound and awakens the whole event of the past in an instant. As Hainge goes on to write:

In Barthes' terms, noise, like the punctum, can bring into being a similar phenomenological event, breaking the studium, dissolving the thetic, piercing the perceiving subject who is henceforth unable to contain it or sublimate this part of expression within an aesthetic or hermeneutic apprehension or appreciation. (2013)

There is no voice in Falling, no speech and therefore no explanation just pulsating and elongated rawness of sound. Noise breaches the boundaries, with the potential to bring the listener deeper in to her/his body and paradoxically thrust her out. There is no choice now but to hear. Falling has no beginning or end, for once experienced the resonance of the sound effects everything that follows and the memory of what preceded it. The imagery, iii shot in black and white, flickers across abstract glimpses of a body falling into a digital abyss of clouds, space and darkness. The sound is an extended and manipulated recording of the Twin Towers collapsing and was extracted from YouTube footage of their actual falling. Certain qualities of the extraction were heightened and deepened, until they resonated through my body, until they could be felt as well as heard. The loudness of the sound interrupts the imagery and breaks it apart into further distortion, and still the body falls, never quite landing yet never fully breaking apart. Noise has pierced the boundaries of the past and the present, turning the body inside out as it tumbles into a future threatened by the impossible realisation of the past. The sound takes possession, isolating the listener, extreme in its loudness it engulfs and takes over. With the boundaries breached, the rupture takes hold. How long will the falling last? How long must this loudness be tolerated? The only choice is to give in, to listen but no sooner does the listener relinquish, she/he is just as quickly ejected and thrown into the next experience.

It is a violent arrival and a violent expulsion in which one is forced to confront the violence of the event. It is, as Catherine Malabou writes, a "suddenly deviant, deviating form," it is "explosive plasticity" (2012). This raises questions. Should Falling lead somewhere? Can something new be created out of this disintegration? And if it can, what language is needed to convey the violence, the conflict between the falling apart and coming together, between self and other, inside and outside. It is a collision with the real that solidifies the space in between, a violent dehiscence of the symbolic in which Falling assumes the digital inscription of the real in time and space. It is the ultimate destructive void, which Freud describes as both: "a mythological phenomenon and as a biological force" (Laub, 2003).

It is the shadow place of Freud's death drive or death instinct, where one is forced to contend with the borderland of survival, this is the state of Nachtraglichkeit, (1865) ${ }^{\text {iv }}$, an in between murky place where the trauma awaits revelation, a challenging space of defence strategies and theatricality where life is lived on the outside to protect a haunted interior. Laub and Lee write about the belated relibidinisation as the constructed and reconstructed revisiting of the traumatic memory until a narrative can be established to integrate the traumatic experience in the most meaningful and resolved way (2013).

Nachtraglichkeit points one backwards to the trauma, structured through a sequence of anticipations and reconstructions:

It may happen that someone gets away, apparently unharmed, from the spot where he has suffered a shocking accident ... In the course of the following weeks, however, he develops a series of grave psychical and motor symptoms, which can be ascribed only to his shock (Freud, 1939).

It is the belated experience constituted by the relationship between two-events or experiences of two competing impulses, that endows the memory rather than the original event with traumatic significance. This time of latency, or what could also be termed an incubation period is an interesting phenomenon. Jean LaPlanche translates Nachträglichkeit as Après-coupl or afterwardsness, a complex interweaving of double meaning and temporality (2001). ${ }^{\vee}$ Afterwardsness is the repetitive insistence of the trauma's constant return in opposition to the flow of life, where the compulsion is to halt the re-experiencing of the traumatic event. Nachträglichkeit is an exchange between two moments, the second of which retrospectively determines the meaning of the first. As understood by Laplanche, it always takes two traumas to make a trauma, where one event is only registered through another in deferred action, which is occasioned by events and situations or by experiences that allow the subject to gain access to a new level of meaning, (1973).

Hal Foster argues that we come to be who we are in deferred action (1996), where the very idea of delay is present from the beginning. Falling signifies the deferred moment, the return and the breach. It both interrupts and captures the interruption. When the flow of time is interrupted, halted, then movement is stagnated, and emergence is denied. Nachträglichkeit steps into 
the space between the disruptive event and the repetitive rupture that returns to restore order, narrative and function. For Lacan it's the missed encounter with the Real that can only be represented in its repetition.

Rather, repetition serves to screen the real understood as traumatic. But this very need also points to the real, and at this point the real ruptures the screen of repetition (Foster, 1996).

Žižek points to the difference between the original and its repetition as the intervention of the "signifying network in which the event is inscribed" (2014). It is only by passing through repetition that the trauma is 'recognised' and as such symbolised.

Falling builds on this intricate temporal interplay of remembering and rupture. Derrida describes nachträglich as that which "turns out to disrupt, disturb, entangle" (1995). The dual temporality and the latency period are essential components of the principle of Nachträglichkeit to facilitate new perceptions of the past. Flashbacks fill this space, they rise to alert, to make sense of the trauma, make one a witness to the traumatic event and one's survival. Falling does this, it reminds me and the audience of the past event, while rising as a flashback to interrupt and disturb. Flashbacks are reminders of one's mortality, of the past one wants to contradictorily remember and forget. Trauma unsettles and forces us to rethink our experiences. Its incomprehensibility makes remembering difficult but forgetting impossible and any form of recollection insufficient.

This raises questions about the aesthetics of 'appropriate' representation. Should it be sensitive recollection, accurate witnessing or something other? With Falling, it was important to throw it all out there, to make the sound as loud as possible, the imagery as fractured and broken as possible. To instil the notion that something is not quite right, or rather that all is not quite right and that the abject can surge forwards at any time and transgress, corrupt and rupture. Making Falling, was not an easy process, it required constant attention to the body (my body), attuning to the rising and falling levels of anxiety, and managing further flashbacks that showed up in dreams, a dissociated sense of the surrounding environment, and the return of rashes and blisters that appeared in the days after 9/11. Caruth articulates this delayed reaction, the repetition of the past:

The experience of trauma, the fact of latency, would thus seem to consist, not in the forgetting of a reality that can hence never be fully known, but in the inherent latency within the experience itself (1995).

The notion of a sonic disturbance, a traumatic fragment of memory, that had existed locked up somewhere inside (or outside) of the body builds upon the complexities of repression and dissociation. Bessel van der Kolk (1995), revisiting Pierre Janet (1894), lays out an interesting hypothesis: "Repression reflects a vertically layered model of mind: what is repressed is pushed downward, into the unconscious" (1995), where it can remain hidden and inaccessible. Whilst dissociation:

reflects a horizontally layered model of mind: when a subject does not remember a trauma, its "memory" is contained in an alternate stream of consciousness, which may be subconscious or dominate consciousness, e.g., during traumatic reenactments (Janet, 1894). (Van der Kolk, 1995)

Freud moves freely between the concepts of repression and dissociation, but as van der Kolk states traumatic memories cannot be both dissociated and repressed (1995). The somatic response to the trigger is what van der Kolk aptly refers to as the body keeping the score (2014). Reminded of what was forgotten, the body is prone to continue the action that was started and prevented from completing when the trauma initially happened. Understanding or integrating the past involves naming and substantiating the absence or the gaps in remembering, inhabiting or re-inhabiting the states of dissociation associated with experiencing traumatic events. Lacanian analysts Francoise Davoine and Jean-Max Gaudilliere have written of a dissociate truth, a "cut out consciousness" (2004) or an unthought known, in which the subject's relationship to history was not so much censored as erased leaving but a trace in the field or the psyche to facilitate a link to the past, a foothold back into the story that has been reduced to nothing. Falling therefore becomes an exploration of the unthought known, an unwinding of the traumatic memory to give some form of language to the trauma body, the traumatic event and its trace. In this instance, the language of noise.

So, does Falling come from a state of repression or dissociation? The confusion was in part the idea that I was experiencing for the first time something that had already been lived through but had been blocked from cognition. What was also intriguing was being able to recall all that was visual whilst blocking the noise (that is until the trigger). The event was incomprehensible but not remembering the obvious loudness was even more disturbing. I was occupying an inverted relationship between space and movement, one that interrupted the natural flow, the impulse towards forward motion. What I began to discover through coming to terms with the remembering, was how the inversion of space and movement shifts the relationship 
between oneself and the experience, thereby creating a rupture beyond comprehension. This body in conflict, caught between the affective and the cognitive registering of the traumatic experience, is trapped within a "conscious automatic" system and an "intensity system". It is a body in a nonlinear process where resonation and affect continue to feedback, "outside expectation and adaptation, as disconnected from meaningful sequencing, from narration, as it is from vital function" (Massumi, 2002). It is a "temporal sink, a hole in time" (ibid), a state of suspense with the potential towards disruption. This body, this site of trauma is a body in-between, a body in crisis caught up in uncertainty where the notion of safety is disrupted, and any organised existence made precarious, a body teetering on the edge haunted by the past.

Falling represents the haunting of the event while simultaneously acting as an anchor of sound and image to force the body to contend with the past. It requires a complex listening, as it both gives and takes away. It offers up the missing sounds and the imagery, broken apart by the sounds, while taking away the security of an aspect of the past that had been firmly held in place for over a decade. Falling, untethers. Voegelin describes noise's ability to force an interaction with the trauma of the real:

Noise is the autistic revelation of war, speechless but focused, producing a heavy weight in a fleeting time (2010).

Listening to the work of noise musician Merzbow, ${ }^{\mathrm{vi}}$ created a tension with what was real. It was to experience the transgression of boundaries with ferocious dissonance, which he himself describes as the "unconsciousness of music" (2004). Steve Wilson theorises that:

Merzbow's expressive noise pushes us beyond structure, beyond the Symbolic, into the realm of jouissance where we confront the terrifying and endlessly enticing unknowable beyond, (2014). vii

That was what I was reliving through hearing Merzbow's noise. To quote Voegelin, I was "[a]cknowledging the abject and contemptible consequences of the technological and societal advancements" of the twentieth century (2010), while coming close to the unknowable beyond.

I struggle with the knowledge of having maintained an aspect of the event in silence for so many years. Awakening to the noise, and therefore the concept of its repression, was not only to accept the violence of the act and therefore the violence of humanity as more than an idea, but also my rejection of the real from presence, a rejection of the void - "the stench and corruption that always yawn like an abyss" (Lacan, 1986/1992). Witnessing the disintegration of the towers from such a close proximity, not only reminded me of the violence that had preceded this event but the violence that was still to come, how powerless I was to prevent it, how small, how impotent and how futile my efforts. It was a trauma, as Derrida writes, "whose temporality proceeds neither from the now that is present nor from the present that is past but from an im-presentable to come (à venir)" (2002). The idea that a worse trauma is yet to arrive defies mourning, and therefore resolution. As Derrida continues:

There is traumatism with no possible work of mourning when the evil comes from the possibility to come of the worst, from the repetition to come - though worse (2002).

The rupture, created by the attack on the World Trade Centre, gave rise to a threat of war that was all pervasive. Running parallel was an underlying sense of fragility, defended against by the extreme measures put in place after 9/11. Measures instigated by the bureau of Homeland Security and the use of colour-coded terror threats, (green denoting low-level threat, red, high level) (CNN, 2011).

In Powers of Horror (1982), Julia Kristeva writes that: "Any crime, because it draws attention to the fragility of the law, is abject." She repeatedly posits a connection between abjection and the border, where abjection is that which disturbs identity, system and order. The abject does not respect borders, positions or rules. It is outside of, literally what is thrown away or discarded. Abjection is ambiguity arising from the impact of a rupture. The abject is neither subject nor object, inside or outside, neither here nor there, rather it is "immoral, sinister, scheming, and shady: a terror that dissembles, a hatred that smiles", "what is abject," she writes, "draws me toward the place where meaning collapses" (1982). To a place of incomprehensibility, in which the contents are actively being erased.

Meaning temporarily collapsed when the towers fell and were razed to the ground. Because of such violence, understanding is outside of comprehension, beyond the borders of language. Laub asserted that 9/11 was "an event without a voice," an "encounter with something that makes no sense" (2003). The erasure of the towers symbolised negation and created a borderland on the edge of New York City, it was a site of destruction, an unrecognisable terrain. Falling brings this all into play. It creates a borderland of fractious noise and imagery, a loss of place in which everything falls apart until nothing remains and one's "entire body falls beyond the limit cadere, cadaver," (Kristeva, 1982). In Falling the emphasis is on the - "Imaginary uncanniness and real threat, it beckons to us and ends up engulfing us" (ibid). Freudian uncanniness: "that class of the 
terrifying which leads back to something long known to us, once very familiar" (Freud, 1919). The uncanny that creates an impossible tension between the desire to reject-ontological spit, and the desire to consume or be consumed. Kristeva connects abjection to the fear and to jouissance:

It follows that jouissance alone causes the abject to exist as such. One does not know it, one does not desire it, one joys in it [on en jouit]. Violently and painfully. A passion (1982).

Voegelin acknowledges this abject and contemptible position and asserts that: "noise now, in its quasi inertia, is not about mass movement and progress but about private and isolated fixity: listening on a heavy spot and pondering that position" (2010).

The title Falling, alludes to the Falling Man a photograph taken by Richard Drew on the morning of September 11th, 2001, of a man leaping to his death from the North Tower. The censorship of the "jumpers" created a contentious discourse around Drew's photograph, which became synonymous with my personal censorship of the noise of the falling Twin Towers. In, The Photographic Message (1977), Barthes acknowledges that traumatic experience can bring about a "suspension of language" and a "blocking of meaning" which photographic representation can distance, sublimate and pacify. Drew's photograph isolated the falling man from the larger landscape of disaster. Its cropping negated the fire and the smoke emblematic of that day and reduced the magnitude of the event to a downward spiraling figure intent on meeting his end. In Falling it seemed important to do the opposite, to open the frame to the noise and chaos, to inhabit the falling, to be aware of one's own vulnerability by confronting the physical cruelty of humanity. As Derrida articulates:

So here, it seems, is what came about what happened to them, then came down to us. And this was an event, perhaps an interminable event (1998).

I experience Falling and I am back there, reexperiencing $9 / 11$ and the unfolding events of the day. I shut my eyes, but the sound continues. Immersed, I become the noise, the sounds of the towers falling and within the noise I am falling over and over with every other being and object that fell from the towers on September 11th. We are all falling together towards some aspect of the other. Falling is my undoing, my corporeal annihilation. In it I lose myself, my separation from the past, swallowed up in the memory, my boundaries, the very skin that I rely on to cover and hold me collapses, and I try unsuccessfully to prevent the approaching ground rise to meet and crush me. In the realisation that I cannot fly, cannot pull up from this downward spiral I am constantly faced with the inevitability of my demise. Falling is a constant reminder that I am both the trauma body and a witness to the trauma body, it moves the trauma in and out of the body. I hear the sound and become the sound as it violently enters me. When I eventually hit the ground by being subsumed by the past, I have no choice but to inhabit a ghostly existence to survive.

Malabou, in her essay Post-Trauma, Towards a New D efinition? (2012), deconstructs Žižek's critique of Freudian and Lacanian ontologies of trauma. Through the concept of "plasticity" as an active embodiment she bridges neuroscience and psychoanalysis to reframe an understanding of trauma. For Malabou, "becoming" is a radical metamorphosis, the fabrication of a new form, person or a way of being in the world. She reformulates the Freudian notion of plasticity as "a new kind of exposure of the nervous system to danger and, consequently, a new definition of what 'event,' 'suffering,' and 'wound' mean" (2013). She writes about negation as having a "clear affective origin: rejection," where, negation is not non-being but thrown out of being. She writes: "In this sense, the repressed or denied is ontological spit. A rejection from presence" (2013). Delaying the hearing of the sound, not only pushes away or rejects the violence of the fall, but also staves off the eventual realisation of the destructive void that has the potential to take over once the sound has finally been heard, as Laub attests, in an interview with Caruth:

Not knowing trauma or experiencing or remembering it [the traumatic event] in a dissociative way is not a passive shutdown of perception or of memory. Not knowing is rather an active, persistent, violent refusal; and erasure, a destructive of form and of representation. The fundamental essence of Freud's death instinct that destroys all psychic structure is apparent in this phenomenon. (2003)

Malabou's gesture of negation expands upon the concept of nothing. Her gesture begins to isolate the violence of the void, or voiding, where nothingness is an active and moving force. Knowing this is begins to unfreeze the trauma. Dylan Trigg writes, in The Aesthetics of Decay: Nothingness, $N$ ostalgia and $t$ he Absence of Reason (2009):

In order for the Nothing to be experienced with greater force, it must arise from a context which violently disjoins with it.

The nothing must be positioned outside, in the aesthetics of silence, before being withdrawn into consciousness (2009: xv). Trigg suggests, from a 
Heideggerian perspective, "nothingness" is not outright negation, neither is it an active force which annihilates nor an absence of presence, but rather "a specific and temporal dynamic which relies on the context that preceded it." $(2009, x v i)$. This connects to Žižek's suggestion that to truly forget a traumatic event, we must find the strength to fully remember, a paradox he accounts for because "the opposite of existence is not nonexistence, but insistence: that which does not exist, continues to insist, striving towards existence" (2001). This constant propulsion towards movement creates the flashback, which lives on in Falling, repeated at each play. A concept that links to Derrida's spectrality - the anachronistic spectre, outside of time and place-which exists between life and death, absence and presence. As Derrida writes "a trace always referring to another whose eyes can never be met" (1995). Searching for the spectral is a way to navigate the evasiveness of trauma, a method of entering the space of dissociation as a witness rather than one subsumed by memory. The spectral for Derrida arises from the concept of a future absence:

To haunt does not mean to be present, and it is necessary to introduce haunting into the very construction of a concept. Of every concept, beginning with the concepts of being and time (1994).

This notion of "hauntology," a pun on "ontology" links being and presence. Through the figure of the ghost, the past and present are indistinguishable. Embodied in the spectral the past is brought to life. Hauntology is the uncanny seeking restitution, an application of which is a necessity in the search for a subjectivity to accommodate the multiplicities of voices and temporalities required to place meaning on traumatic experience. Falling is the spectral seeking resolution. It is the ghostly haunting of the past, returning to be witnessed over and over. The ghost: "the double (and its various manifestations such as mirror images, déjà vu, doppelgangers, out of body experiences, etc.)" neither claims to be nor is experienced as a replica or a representation of the self as Freud posits, but rather the "ghost disturbs by producing an uncanny version of the other" (Rahimi, 2015). This notion of haunting suggests the idea of an externalisation of the haunted interior and creates the potential for a narrative to exist outside of the body, perhaps as an alternative to negotiate not only individual trauma, but also intergenerational and collective trauma. Can Falling offer that space? As it haunts, jars, and reverberates can it also, through the loudness create a space outside of trauma?

In Spectres of Marx, Derrida considers the conflict between presence and absence, inside and outside. He argues that the true logic of uncanniness is a phantom-logic, a necessity of learning to live with ghosts, phantoms, and spirits, because "there is no Dasein without the uncanniness, without the strange familiarity [Unheimlichkeit] of some spectre" (1994). It is a state of being that is to be always and everywhere haunted by ghosts, phantoms or spirits: the "visibility of the invisible" (ibid). Spectral logic is the presence related to the otherness of the self, or the self that is found within the other. In honour of Barthes, he writes: "Ghosts: the concept of the other in the same, the punctum in the studium, the completely other, dead, living in me". This ghostly punctum is linked to the voice of the other, it is the "accompaniment, the song, the accord" (2003).

\section{CONCLUSION}

To sum up, memory is complex, trauma even more so. Remembering through Falling turns the body inside out, changing and reframing the memory and therefore the relationship to the event. Falling requires a heavy listening. It anchors and casts out, isolates and embraces, "a burden both repellent and repelled, a deep well of memory that is unapproachable and intimate: the abject" (Kristeva, 1982). Falling succeeds in capturing the abject, while continuing to rupture the present. But it also achieves something else, it creates a porthole into the past, enough of a space to relive the event without having to go back there. It occupies a place outside of space and time, an in-between space neither here, nor there, now nor then. Falling moves beyond Freud's concept of Nachträglichkeit because it does more than disturb or disrupt, it also creates a safe space, each listening functions to ground and centre. Its noise moves through me, down into the earth. It bears down on me with force, creating a sense of aliveness and connectedness. It activates not the trauma response, but quite the opposite, hope. It frees me. Falling begins to lay a foundation for mourning, it creates space to understand the loss of the body and self that existed before the event and the loss of the body to the event. It sets up the beginnings of an ongoing process to put the past to rest, as Derrida writes:

There is also a mode of production of the phantom, itself a phantomatic mode of production. As in the work of mourning, after a trauma, the conjuration has to make sure that the dead will not come back (2006).

\section{REFERENCES}

Bergson, H. (2004) Matter and Memory. Dover Publications, Inc. Mineola, New York.

Caruth, C. (ed.) (1995) Trauma, Explorations in Memory. Johns Hopkins University Press, Baltimore. 
Caruth, C. (ed.) (2014) Listening to Trauma. Conversations $w$ ith $L$ eaders in the Theory and Treatment of $\mathrm{C}$ atastrophic Experience Mem ory. Johns Hopkins University Press, Baltimore.

Davoine, F., and Gaudilliere, JM. (2004) History Beyond Trauma. Translated by $S$. Fairfield. Other Press, New York.

Derrida, J. (1993/ 1994) Specters of Marx. Translated by P. Kamuf. Routledge, New York [etc.]

Derrida, J. (2001). The Work of Mourning. Translated by P.A. Brault and M. Naas. The University of Chicago Press, Chicago [etc.]

Freud, S., and Breuer, J. (1893/ 2004) Studies in Hysteria. Translated. N. Luckhurst. Penguin Books, London.

Freud, S., Reddick, J. and Edmundson, M. (2003) Beyond the Pleasure Principle and Other Writings. Penguin Books, London.

Freud, S. (1926/ 1977) Inhibitions, Symptoms, and Anxiety Beyond the Pleasure Principle (The Standard Edition) (Complete Psychological Works of Sigmund Freud) W. W. Norton \& Co., London.

Freud, S. (1919) The Uncanny. http://web.mit.edu/ allanmc/www/freud1.pdf (1/12/ 2015).

Freud, S. (1950 [1895]). Nachtraglichkeit - Project for a Scientific Psychology. http://www.lacanianworks.net/?p=401 (25/6/2015).

Foster, H. (1996) The Return of the Real. The MIT Press, Cambridge, MA.

Hainge, G. (2013) Noise Matters: Towards and Ontology of Noise. Bloomsbury Academic, New York and London.

Kristeva, J. (1982) Powers of Horror, An Essay on Abjection. Translated by L.S. Roudiez. Columbia University Press, New York.

Laplanche, J. and Pontalis. (1946/1990) The Language of Psychoanalysis in (ed.) Fenichel $O$. The $P$ sychoanalytic Theory of $N$ eurosis $50 t h$ Anniversary Edition. Routledge, New York.

Laub, D. and Lee, S. (2003) Thanatos and Massive Psychic Trauma: The Impact of the Death Instinct on Knowing, Remembering and Forgetting. Journal of the American Psychoanalytical Association, 51(2) pp. 433-464.

Laub, D. (2009) On Holocaust Testimony and Its "Reception" within Its Own Frame, as a Process its Own Right: A Response to "Between History and Psychoanalysis" by Thomas Trezise. History \& Memory 21(1), pp. 127-150.
Malabou, C. and Miller, S. (2012) The New Wounded. Fordham University Press, New York.

Malabou, C. (2009) Plasticity and Elasticity in Freud's 'Beyond the Pleasure Principle.' Parallax.

http://www.tandfonline.com/action/journallnformatio n?journalCode=tpar20 (23/1/2016).

Massumi, B. (2002) Parables for the Virtual Movement, Affect, Sensation. Duke University Press, London [etc.].

Rahimi, S. (2015) Ghosts, Haunting, and Intergenerational Transmission of Affect: From Cryptonymy to Hauntology. http://psychoanalyticdiscourse.com/index.php/ps ad/article/view/21/22 (23/1/2016).

Trigg, D. (2006). The Aesthetics of Decay: Nothingness, Nostalgia, and the Absence of Reason (New Studies in Aesthetics). Peter Lang Publishing Inc, New York.

Voegelin, S. (2005). Pondering a Paradox: The Seduction of Noise, paper presented at NoiseTheoryNoise2 conference. http://salomevoegelin.net/public_html/salomevoe gelin.net/pondering.html (3/5/2016)

Voegelin, S. (2010) Listening to Noise and Silence: Towards a Philosophy of Sound Art. Continuum, New York and London.

Žižek, S. (2002) Welcome to the Desert of the Real! Five Essays on September 11 and Related Dates. Verso, London.

\footnotetext{
${ }^{\mathrm{i}}$ Voegelin, S. 27-29 June 2012. Neuro Arts, arts + sound symposium, Plymouth University.

ii https://vimeo.com/354474318 Password: Anna

iii The imagery for Falling was filmed from YouTube footage of Joseph Kittinger, The Man Who Fell From Space (1960).

iv 'Is it not true that the logic of the after-the-fact (Nachträglichkeit) which is not only at the heart of psychoanalysis, but even, literally, the sinews of all 'deferred' (nachträglich) obedience, turns out to disrupt, disturb, entangle forever the reassuring distinction between the two terms of this alternative, as between the past and the future, that is to say, between the three actual presents, which would be the past present, the present present, and the future present?' (Derrida, 1998)

${ }^{\mathrm{v}}$ What Freud tried to discover, through

Nachträglichkeit, is something much more connected with the whole of a life. That is another type of temporality. It is the temporality of retranslating one's own fate, of retranslating what's coming to this fate from the message of the other. That's a completely different aspect of temporality. (La Planche, 2001)

vi Born Masami Akita. 1956.

vii italics mine
} 